\title{
Immediate effects of cervical stimulation and diaphragmatic release on vocal production
}

\author{
Efeitos imediatos da estimulação cervical $e$ \\ liberação diafragmática na produção vocal
}

\author{
Érika Corrêa Machado [D] ${ }^{[a]}$, Letícia Fernandez Frigo ${ }^{[b]}$, Fernanda Anversa Bresolin (iD [b], \\ Joziane Padilha de Moraes Lima [i] ${ }^{[b]}$, Carla Aparecida Cielob $\mathbb{B}[\mathrm{b}] *$
}

[a] Centro Universitário Franciscano (UNIFRA), Santa Maria, RS, Brazil

[b] Universidade Federal de Santa Maria (UFSM), Santa Maria, RS, Brazil

\section{Abstract}

Introduction: The voice is heavily influenced by breathing and abdominal muscles. Objective: To verify the immediate effects of cervical stimulation and diaphragmatic release on the respiratory and phonatory function of adult women with no vocal complaints. Method: Relaxation maneuvers and eccentric work of the diaphragm were performed together with articulatory maneuver of the third cervical vertebra. Twentyfour women without vocal complaints, aged between 18 and 35 years were part of the intervention. All volunteers were submitted to an evaluation of respiratory muscle strength, maximum phonation time of the vowel /a/, sound pressure level and acoustic vocal analysis, before and after physiotherapeutic intervention. Statistical analysis consisted of the Student's t-test for independent samples and Spearman's correlation. Significance level was set at 5\%. Results: There was a significant increase in the maximum phonation time of the vowel /a/ and in the modal sound pressure level. Regarding the acoustic analysis, there was a reduction in the standard deviation values of the fundamental frequency; in the smoothed pitch disturbance

*ECM: BS, e-mail: erika.cmachado92@gmail.com

LFF: PhD, e-mail: leticia_frigo@hotmail.com

FAB: Master's Student, e-mail: fernandaanversabresolin@gmail.com

JPM: PhD, e-mail: jozimoraeslima@gmail.com

CAC: PhD, e-mail: cieloca@yahoo.com.br 
quotient; and in the fundamental frequency and amplitude variations. Conclusion: Cervical stimulation and diaphragmatic release improved vocal quality regarding duration of emission, sound pressure, and stability and noise of the glottic signal.

Keywords: Acoustic. Diaphragm. Physical Therapy. Breathing. Voice.

\section{Resumo}

Introdução: A voz é muito influenciada pela respiração e pela musculatura abdominal. Objetivo: Verificar os efeitos imediatos da estimulação cervical e liberação diafragmática na função respiratória e fonatória de mulheres adultas sem queixas vocais. Método: Realizaram-se manobras de relaxamento e trabalho excêntrico do diafragma junto a uma manobra articulatória da terceira vertebra cervical. Fizerem parte da intervenção 24 mulheres sem queixas vocais, com idades entre 18 e 35 anos. Todas as voluntárias foram submetidas a uma avaliação de força da musculatura respiratória, do tempo máximo de fonação da vogal /a/, do nível de pressão sonora e análise vocal acústica, pré e pós-intervenção fisioterapêutica. Foram realizados os testes t-student para amostras independentes e correlação de Spearman com nível de significância de 5\%. Resultados: Verificou-se aumento significativo no tempo máximo de fonação da vogal de /a/ e do nível de pressão sonora modal. Na análise acústica, houve redução dos valores do desvio-padrão da frequência fundamental; do quociente de perturbação do pitch suavizado; da variação da frequência fundamental e da variação da amplitude. Conclusão: As manobras fisioterapêuticas de estimulação cervical e liberação diafragmática melhoraram a qualidade vocal em relação ao tempo de sustentação da emissão, à pressão sonora, à estabilidade e ao ruído do sinal glótico.

Palavras-chave: Acústica. Diafragma. Fisioterapia. Respiração. Voz.

\section{Introduction}

The voice is defined as a result of the sounding of pulmonary air through vocal folds and its passage through the resonant cavities. Respiratory muscle activity and the integrity of all tissues of the speech apparatus are essential for its production. In addition, vocal emission requires the interaction between different systems of the human body, since there is no specific system or device for voice production [1-4].

The phonatory function is then superimposed on the stomatognathic system - a set of structures that performs the functions of chewing, sucking, swallowing and speaking - and on the respiratory system that works like a pump, producing air flow and pressure in order to excite the vibratory mechanism. Hence, exhaled air corresponds to the source that triggers the vibration of the vocal folds. Any change in the structural or functional conditions of such systems may impact vocal production [1-7].

Since the exhalation of pulmonary air acts as a source of vocal emission, with direct effect on the voice, the expiration must be sufficient and sustained in order to maintain an adequate dynamic between the respiratory, phonatory and articulatory levels of vocal production. Such air support depends on abdominal and chest muscles. Breathing requires the coordination of large muscle groups that are innervated mainly by the cervical and thoracic spine [8-13].

The diaphragm is innervated by the phrenic nerve at cervical levels $\mathrm{C} 3, \mathrm{C} 4$ and $\mathrm{C} 5$, and takes a primordial place during the respiratory cycle [13]. The contraction of the diaphragm moves abdominal content downwards and transmits lateral forces that cause rib cage to expand inferiorly, anteroposteriorly and laterally during inspiration. This contraction compresses the viscera and, simultaneously, reduces pressure on the lungs, increasing their volume and favoring active air inhalation. For phonation to occur during expiration, the adduction of vocal folds in the midline and the formation of subglottic air pressure are paramount. These must be sufficient and sustained in order to trigger voice production with glottic vibration [14-16].

Some physiotherapeutic techniques are intended to stimulate the phrenic nerve $(\mathrm{C} 3, \mathrm{C} 4, \mathrm{C} 5)$ and, when associated with maneuvers to release the diaphragm muscle, help in the synergism between the descent of 
said muscle and chest mobility. This improves inspiratory and expiratory patterns, as it allows greater range of movement of the rib cage and improvement of diaphragmatic positioning [15-18].

Changes in respiratory mechanics may lead to the hypertension of the diaphragmatic muscles, causing a decrease in air flow and incorrect glottic adduction. This leads to an imbalance between respiratory support and laryngeal mechanisms, and therefore changes the subglottic pressure necessary for vibration of the vocal folds [19]. The reduction in subglottic pressure may generate an increase in laryngeal tension due to the effort of the adductor muscles of the vocal folds in an attempt to perform vocal production with insufficient expiratory support [20-21].

Inefficient breathing, when associated with altered vocal demand, can contribute negatively to vocal production, as it generally causes greater laryngeal effort that will trigger laryngeal disorders. Furthermore, changes in the breathing pattern may decrease diaphragmatic potential and cause inspiratory block, impairing respiratory lung function. This causes changes in lung volume, which may affect maximum phonation time (MPT) and sound pressure level (SPL) [20-23].

Based on the aforementioned, the present study intended to act in a multidisciplinary view between Physiotherapy and Speech Therapy, comparing and correlating the immediate effects of cervical stimulation and diaphragmatic release on the respiratory and phonatory functions of adult women without vocal complaints.

\section{Method}

This research was a transversal, contemporary, almost experimental, quantitative study, approved by the Research Ethics Committee of the institution of origin (n. 718.857).

The sample was accidental non-probabilistic, and the inclusion criteria were: female gender, aged between 18 and 40 years, and agreement with the Free and Informed Consent Form. The exclusion criteria were: presence of vocal or hearing complaints, reports of smoking and/or alcoholism, being pregnant and/or being a voice professional (teachers, singers, broadcasters and telemarketing operators, among others). The invitation was carried out online, where the inclusion and exclusion criteria, and the realization of the physiotherapy technique were made clear. An initial interview was performed using an evaluation form containing the anamnesis with personal data and characteristics of the subject, in order to apply the inclusion and exclusion criteria. Thus, the sample consisted of 24 women between the ages of 18 and 35 years.

For data collection, a sphygmomanometer and a stethoscope were used in order to control vital signs before and after the intervention. The evaluations described below were performed on the same day with a rest interval of $30 \mathrm{~s}$ to $1 \mathrm{~min}$ between repetitions, and a longer break between tests, considering the volunteer's effort [8].

A digital manovacuometer (MDI ${ }^{\circledR}$ Globalmed, MVD300) with an operational scale in $\mathrm{cmH}_{2} 0$ (resolution $1 \mathrm{cmH}_{2} 0$, capacity $300 \mathrm{cmH}_{2} 0$ ) was used to assess the maximum expiratory and inspiratory pressure measurements (MEP and MIP, respectively). This equipment was used with a sterile mouthpiece and the participants' nostrils were occluded with a nasal clip. In order to perform the measurements, all subjects remained seated, with the upper limbs relaxed $[19,22,23]$.

In order to assess MEP, the volunteers were instructed to inhale to full lung capacity and, afterwards, to exhale with maximum effort into the mouthpiece. They were also instructed to avoid the collapse of the cheeks during measurement so as not to raise the pressure of the oral cavity [19]. For the assessment of MIP, a maximum inspiration in the mouthpiece was requested from the residual volume and, subsequently, an exhalation in the mouthpiece [19].

The measurements were repeated three times and the highest value among the three attempts was used to calculate the MIP and MEP values, as long as it did not exceed $10 \%$ of the second highest value. The formula described in the literature was used to stipulate the predicted value according to gender and age [19-22]. These measurements were conducted by a previously trained Physiotherapy intern.

To collect MPT/a/ data, a microphone (Behringer ECM 8000 with flat frequency response from $15 \mathrm{~Hz}$ to $20 \mathrm{kHz}$ ) was used coupled to a professional digital recorder (Zoom H4n - 96kHz, 16 bits, $50 \%$ of the level of input signal). This evaluation was performed by a speech therapist with each volunteer in an orthostatic position in order to allow free respiratory expansion. The microphone coupled to the recorder was positioned at a $90^{\circ}$ angle and at a distance of $4 \mathrm{~cm}$ from the mouth for the emission of the vowel [22]. The participant was instructed, after a maximum inspiration, to sustain throughout an exhalation in pitch (subjective sensation of frequency) and loudness (subjective sensation of sound pressure) usual to vowel /a/, recorded and timed in seconds. The vowel was sustained three times, with the highest value being chosen in seconds as MPT/a/ [22-28]. 
On this same occasion, the usual SPL was measured with a sound pressure meter (Instrutherm, Dec-480), positioned in front of the body at $30 \mathrm{~cm}$ from the mouth, during the emission of the vowel /a/, considering the modal value [8].

MPT/a/ was also analyzed acoustically using the Multi-Dimensional Voice Program Advanced (MDVPA) from KAY PENTAX ${ }^{\circledR}$. The capture rate was $44 \mathrm{kHz}$ and 16 bits of analog-to-digital conversion, analyzing the frequencymeasures: fundamental frequency (f0), maximum f0 (fhi), minimum f0 (flo), standard deviation of f0 (STD); frequency disturbance measures: absolute jitter (Jita), percentage or relative jitter (Jitt), relative average of pitch perturbation (RAP), pitch perturbation quotient (PPQ), smoothed pitch perturbation quotient (sPPQ), variation of $\mathrm{f0}$ (vf0); amplitude disturbance measures: Shimmer in dB (ShdB), percentage shimmer (Shim), amplitude perturbation quotient (APQ), smoothed amplitude perturbation quotient (SAPQ), amplitude variation (vAm); noise measures: noise-harmonic ratio (NHR), voice turbulence index (VTI), soft phonation index (SPI); voice break measures: degree of vocal breaks (DVB), number of vocal breaks (NVB); measures of unvoiced segments: number of unvoiced segments (NUV), degree of unvoiced segments (DUV); sub-harmonic segment measurements: degree of sub-harmonic components (DSH), number of sub-harmonic segments (NSH). The reference values for the female f0 measurement were considered those in the range of 150 to $250 \mathrm{~Hz}$ [8-21].

The physiotherapeutic intervention took place as follows: a rhythmic cervical articulation technique was performed at the $\mathrm{C} 3$ level, when the volunteer was asked to assume the supine position on the stretcher, with upper and lower limbs relaxed. The therapist positioned herself cranially to the volunteer, wrapping her hands around the neck, leaving the indicators close to the C3 vertebra and its inter-facet joint (in the posterior region of the vertebra). Subsequently, passive movements were performed in a rhythmic and smooth manner with three repetitions for the $\mathrm{C} 3$ interfacial joint, with mobilizations from one side to the other, associating lateral sliding (translation) and rotation, forming movements in "8" in the axial view, repeated 3 times [22].

In a second moment, eccentric work was applied on the diaphragm, with the volunteer in the supine position, with her head elevated and her knees flexed on the stretcher. The therapist positioned herself cranially to the volunteer, with her fingers placed under the costal edges, and a deep inspiration was requested. During exhalation, the therapist prevented the ribs from descending and kept them apart. The maneuver ended when the therapist felt the relaxation of the diaphragmatic muscles with her hands [15-20].

In a third step, the diaphragmatic relaxation technique was applied, in which the therapist positioned herself caudally to the volunteer and her hands remained in a neutral position, supporting the distal phalanges in the region of the lower edge of the lower ribs of the volunteer. The technique consisted of gentle and progressive pressures on the lower edge of the lower ribs and this pressure continued towards the volunteer's navel. Pressure was exerted when an exhalation occurred. At the end of exhalation and the beginning of inspiration, the pressure was maintained; when starting a new expiration, a new pressure was applied. The technique ended when the fascial tissue and the diaphragmatic muscle showed relaxation [15-21].

The average duration of the session was 45 minutes.

Immediately after applying the therapeutic techniques, the aforementioned assessments were redone.

Data analysis was performed using descriptive statistics (average and standard deviation), Student's t-test for independent samples, and Spearman correlation, using the BioEstat software (version 5.3). Significance was set at $5 \%$.

\section{Results}

Table 1 shows the statistical comparison of acoustic vocal measures from glottic source before and after physical therapy intervention.

Table 1 - Comparison of acoustic vocal measures from glottic source through the Multi-Dimensional Voice Program Advanced between pre and post physiotherapeutic intervention

\begin{tabular}{lccc}
\hline $\begin{array}{c}\text { MDVPA } \\
\text { Measurements }\end{array}$ & $\begin{array}{c}\text { Pre- } \\
\text { intervention } \\
\text { average }\end{array}$ & $\begin{array}{c}\text { Post- } \\
\text { intervention } \\
\text { average }\end{array}$ & p-value \\
f0 (Hz) & 218.077 & 222.188 & 0.122 \\
fhi (Hz) & 232.24 & 234.263 & 0.654 \\
flo (Hz) & 205.087 & 211.160 & 0.087 \\
STD f0 (Hz) & 3.153 & 2.636 & $0.021^{*}$ \\
Jita (us) & 50.885 & 42.977 & 0.082 \\
Jitt (\%) & 1.101 & 0.950 & 0.120 \\
RAP (\%) & 0.667 & 0.573 & 0.114 \\
PPQ (\%) & 0.639 & 0.559 & 0.160 \\
SPPQ (\%) & 0.768 & 0.660 & $0.035^{\star}$ \\
vf0 (\%) & 1.445 & 1.186 & $0.009^{\star}$ \\
& & & (to be continued)
\end{tabular}

Fisioter Mov. 2020;33:e003337 


\begin{tabular}{lclc}
\hline & & & (conclusion) \\
ShdB (dB) & 0.354 & 0.352 & 0.950 \\
Shim (\%) & 4.002 & 3.990 & 0.951 \\
APQ (\%) & 2.896 & 2.871 & 0.867 \\
SAPQ (\%) & 5.008 & 4.757 & 0.270 \\
VAm (\%) & 18.609 & 11.681 & $0.000^{*}$ \\
NHR (\%) & 0.133 & 0.138 & 0.339 \\
VTI & 0.049 & 0.046 & 0.621 \\
SPI & 7.532 & 7.971 & 0.586 \\
DVB (\%) & 0.031 & 0.000 & 0.327 \\
DSH (\%) & 0.307 & 0.791 & 0.737 \\
DUV (\%) & 0.025 & 0.076 & 0.424 \\
NVB (\%) & 0.083 & 0.000 & 0.327 \\
NSH (\%) & 0.708 & 1.292 & 0.531 \\
NUV (\%) & 0.083 & 0.000 & 0.327 \\
\hline
\end{tabular}

Note: *statistically significant values $(\mathrm{p}<0.05)$; Student's t-test. Label: MDVPA: Multi-Dimensional Voice Program Advanced; r: correlation coefficient value; $p$ : statistical significance; f0: fundamental frequency; fhi: maximum f0; flo: minimun f0; STD: standard deviation of f0; Jita: absolut Jitter; Jitt: percentage or relative Jitter; RAP: relative average of pitch perturbation; $\mathrm{PPQ}$ : pitch perturbation quotient; $\mathrm{SPPQ}$ : smoothed pitch perturbation quotient; vf0: variation of $\mathrm{fO}$; ShdB: absolute Shimmer in dB; Shim: percentage Shimmer; APQ: amplitude perturbation quocient; SAPQ: amoothed amplitude perturbation quotient; vAm: amplitude variation; NHR: noise-harmonic ratio; VTI: voice turbulence index; SPI: soft phonation index; DVB: degree of vocal breaks; DSH: degree of su-harmonic components; DUV: degree of unvoiced segments; NVB: number of vocal breaks; NSH: number of sub-harmonic segments; NUV: number of unvoiced segments;\%:percentage; $\mathrm{dB}$ :decibel; Hz:Hertz; us:microsecond.

Table 2 shows the statistical comparison of the measures of MPT/a/, modal SPL and respiratory pressures before and after physical therapy intervention.

Table 2 - Comparison of maximum phonation time of /a/, modal sound pressure level and respiratory pressures before and after physiotherapeutic intervention

\begin{tabular}{lccc}
\hline & $\begin{array}{c}\text { Pre- } \\
\text { intervention } \\
\text { average }\end{array}$ & $\begin{array}{c}\text { Post- } \\
\text { intervention } \\
\text { average }\end{array}$ & p-value \\
\hline $\begin{array}{l}\text { Maximum } \\
\text { Phonation Time of }\end{array}$ & 12.05 & 14.57 & $0.000^{*}$ \\
$\begin{array}{l}\text { a/ (s) } \\
\text { Modal Sound }\end{array}$ & & & \\
Pressure Level (dB) & 66.67 & 69.50 & $0.000^{\star}$ \\
MIP $\left(\mathrm{cmH}_{2} \mathbf{0}\right)$ & 66.25 & 69.33 & 0.105 \\
MEP $\left(\mathrm{cmH}_{\mathbf{2}} \mathbf{0}\right)$ & 90.41 & 91.20 & 0.784 \\
\hline
\end{tabular}

Note: * statistically significant values $(p<0.05)$. Student's t-test Label: MEP: maximum expiratory pressure; MIP: maximum inspiratory pressure; $\mathrm{s}$ : second; $\mathrm{dB}$ : decibel; $\mathrm{CmH}_{2} \mathrm{O}$ : centimeters of water.

\section{Discussion}

After the application of a rhythmic maneuver on the cervical joint, which stimulated phrenic innervation, and after diaphragmatic maneuvers [15-25], there was a significant increase in MPT/a/ and modal SPL values, as well as in those obtained from the acoustic vocal analysis. A reduction in STD, sPPQ vf0 and vAm values was observed (Tables 1 and 2).

The cervical stimulus maneuver applied to the volunteers may have activated the phrenic nerve with improved respiratory activities, such as pulmonary rhythm and coordination, due to its motor stimulus. In addition, the diaphragmatic release technique possibly provided muscle balance to the diaphragm and elongated its muscle fibers, increasing the expansion of the rib cage and lung volume $[1,2,15,24,26]$, although with no significant effect on MIP and MEP (Table 2).

The elongation of the diaphragmatic fibers promotes greater use of the pulmonary area, providing an increase in expiratory air flow, greater respiratory coordination and, consequently, longer MPT. The MPT shows the control between the aerodynamic forces of the lung and the myoelastic forces of the larynx. In fact, any changes in 
one of these levels can promote the increase or decrease of MPT measurements. The muscular balance obtained with the applied physiotherapeutic maneuvers provides greater control and expiratory efficiency, which favored the increase in MPT values [1-27].

Increases in aerodynamic power and/or greater adductor contractions of the vocal folds can increase SPL values. Thus, the increase observed in this study may be related to these two aspects, since the increase in airflow and better muscle control at expiration promotes greater glottic resistance, contributing to the increase in subglottic pressure and, therefore, SPN $[19,28]$.

The physiology of the physical therapy techniques performed may justify the significant improvements found in the vocal acoustic analysis. The increase in airflow and better muscle control during expiration promotes the reduction of tension in the laryngeal region and the continuity of airflow directed to the larynx, which can affect phonation stability (improvement of the STD, vf0 and vAm measures) and phonation quality regarding the decrease of aperiodic energy in the sound signal (improvement of sPPQ measurement) [19-22-27].

Although not statistically significant, it is noteworthy that most vocal acoustic measures and respiratory pressures improved after the physical therapy intervention, reinforcing the importance of the performed maneuvers and the benefits of the procedure at phonatory and respiratory levels. The literature highlights that aerodynamic factors have a positive relationship with acoustic parameters from glottal source [15,19,29,30] (Tables 1 and 2).

Considering the positive and significant results found in the present study, although without significant correlation between variables studied (Table 3), it appears that researches involving cervical stimulation and diaphragmatic release are of great importance for the theoretical and practical clinical basis. Both Physiotherapy and Speech Therapy can benefit from such multidisciplinary work and, therefore, improve treatment and prognosis of patients.

The main limitation of this study is the small sample size, given the careful selection of the sample. Future studies with larger sample and with a longer intervention time are necessary (longitudinal study).

\section{Conclusion}

The physiotherapeutic maneuvers of cervical stimulation and diaphragmatic release improved vocal quality regarding the sustaining emission time of vowel /a/, sound pressure, and stability and noise of the glottal signal, evidencing influence on the vocal production of adult women.

\section{Acknowledgement}

This study was financed in part by the Coordenação de Aperfeiçoamento de Pessoal de Nível Superior Brasil (CAPES) - Finance Code 001. C. A. Cielo acknowledges support from Brazilian agency CNPq (Grant 301326/2017-7).

\section{References}

1. Behlau MS, Azeveldo R, Pontes P. Voice assessment. In: Behlau MS. Voice: the specialist's book. Rio de Janeiro: Revinter; 2013; p. 85-245.

2. Behlau MS, Madazio G, Moreti F, Oliveira G, Santos LMA, Paulinelli BR, et al. Efficiency and Cutoff Values of SelfAssessment Instruments on the Impact of a Voice Problem. J Voice. 2016;30(4):506-9.e9-506.e18.

3. Fontana P, Marin L. The influence of a respiratory training program on the vocal quality and lung function of participants in the Coral Unochapecó. Rev Fisi Senectus. 2013;1(2):25-33.

4. Souza LBR, Santos MM. Body mass index and acoustic voice parameters: is there a relationship? Braz J Otorhinolaryngol. 2018;84(4):410-5.

5. Behlau MS, Pontes M, Moreti F. Higiene Vocal - Cuidando Da Voz. Rio de Janeiro: Revinter; 2017.

6. Genilhú PDFL, Gama ACC. Acoustic and aerodynamic measures in singers: a comparison between genders. CoDAS. 2018;30(5):1-6.

7. Andriollo DB, Frigo LF, Moraes AB, Cielo CA. Forced vital capacity and maximum respiratory pressures of professional popular singers. Fisioter Bras. 2019;20(1):70-6.

8. Jiménez Y. The relationship of sagittal dentomaxillofacial anomalies with body posture and plantar support. Rev Med Electron. 2018;40(3):602-14. 
9. Frigo LF, Cielo CA, Lima JPM, Braz MM. Body power center, maximum phonation time and sound pressure of healthy women. Audiol Commun Res. 2017;22(1):1685-

10. Chamun WWA. The construction of vocal performance in Brazilian Portuguese in three models: lyrical, chamber and belting: pedagogical strategies. Acervo Universidade Estadual Paulista. São Paulo: UNESP; 2017.

11. Porolnik S, Braz MM, Padilha JF, Seidel EJ. Core and respiratory muscles activation in elderly women with and without stress urinary incontinence. Fisioter Bras. 2015;16(2):101-6.

12. Santana PV, Prina E, Albuquerque ALP, Carvalho CRR, Caruso P. Identifying decreased diaphragmatic mobility and diaphragm thickening in interstitial lung disease: the utility of ultrasound imaging. J Bras Peneumol. 2016;42(2):88-94.

13. Cielo CA, Christmann MK, Ribeiro VV, Hoffmann CF, Padilha JF, Steidl EMS, et al. Musculoskeletal stress syndrome, extrinsic laryngeal muscles and body posture: theoretical considerations. Rev CEFAC. 2014;16(5):1639-49.

14. Veron HL, Antunes AG, Milanese JM, Correa ECR. Implications of mouth breathing on the pulmonary function and respiratory muscles. Rev CEFAC. 2016;18(1):242-51.

15. Nascimento VC, Teixeira RC, Sousa EC, Gomes ELFD, Costa D. Effect of resistance training on physical performance and functional respiratory capacity of elderly women. J Sport Health Sci. 2018;29:e2943.

16. Stelle R, Zeigelboim BS, Lange MC, Marques JM. Influence of manipulation at range of rotation of the cervical spine in chronic mechanical neck pain. Rev Dor. 2013;14(4):284-9.

17. Barbosa DR, Silva FJM, Pinto JMS. The influence of the myosfascial liberation and the phrenic nerve techniques in the diaphragm function. Rev Ter Man. 2008. 6(23):6-10.

18. Gava JW, Ferreira LP, Silva MAA. Support and singing voice: perspective of singing teachers and speech language pathologists. Rev CEFAC. 2010;12(4):557-62.

19. Boschi ES, Lima DC. Effects of thoracic manipulation on pain and cervical spine movement amplitude. Cippus. 2012;1(1):78-91.

20. Onaga FI, Jamani M, Ruas G, Lorenzo VAPD, Jamani LK. Influence of different types of mouthpiece and diameters of trachea in the manovacuometry. Fisioter Mov. 2017;23(2):110-7.
21. Brum DM, Finger LS, Manfrin JA, Cielo CA. Considerations regarding vocal and laryngeal modifications caused by vocal fry in women without voice complaints. Rev Soc Bras Fonoaudiol. 2010;15(2):282-8.

22. Siqueira, LTD. Effectiveness of transcutaneous electrical nerve stimulation (TENS) in voice therapy of dysphonic women: control, randomized and double blind clinical trial [dissertation]. São Paulo: Universidade de São Paulo; 2016.

23. Cielo CA, Frigo LF, Christmann MK. Sound pressure level and maximum phonation time after finger kazoo technique. Rev CEFAC. 2013;15(4):994-1000.

24. Pessoa IMBS, Pereira HLA, Aguiar LT, Tagliaferri TL, Silva LAM, Parreira VF. Test-retest reliability and concurrent validity of a digital manovacuometer. Fisioter Pesq. 2014;21(3):236-42.

25. Busquet $M$. The physiological chains, the visceral chain, chest, throat, mouth. ed. São Paulo: Manole; 2009.

26. Sirasanagandla SR, Nayak SB, Bhat KMR, Surendran S, Regunathan D, Kumar N, et al. Duplicated right crus of the diaphragm: a cadaveric case report. J Can Chiropr Assoc. 2014;58(1):39-44.

27. Jarosz R, Littlepage MM, Creasey G, Mckenna S. Functional electrical stimulation in spinal cord injury respiratory care. Top Spinal Cord Inj Rehabil. 2012;18(4):315-21.

28. Arunachalam R, Boominathan P, Mahalingam S. Clinical voice analysis of carnatic singers. J Voice. 2014;28(1):128-36.

29. Meenan K, Catanoso L, Aoyama J, Stephan SR, Chauvin $\mathrm{R}$, Sataloff RT. The utility of pulmonary function testing in patients presenting with dysphonia. J Voice. 2019;(33)4:567-74.

30. Neder JA, Andreoni S, Lerario MC, Nery LE. Reference values for lung function tests II. Maximal respiratory pressures and voluntary ventilation. Braz J Med Biol Res. 1999;32(6):719-27.
Received: 06/11/2019

Recebido: 11/06/2019

Approved: 02/03/2020

Aprovado: 03/02/2020 